\title{
Static analysis of dump truck chassis frame made of composite materials
}

\author{
Adem Siraj ${ }^{1}$, N. Ramesh Babu ${ }^{2}$, K. Sirinivasa Reddy ${ }^{3}$ \\ ${ }^{1}$ Department of Mechanical Engineering, Mettu University, ETHIOPIA \\ ${ }^{2}$ Department of Mechanical and Vehicle Engineering, Adama Science and Technology University, ETHIOPIA \\ ${ }^{3}$ Department of Mechanical Engineering, Defense Engineering University, ETHIOPIA \\ Corresponding Author's e-mail: aduyyee12@gmail.com
}

\begin{abstract}
For a heavy vehicle, the chassis frame is a strong member responsible for carrying the utmost lead in a safe manner when considering all the designed working situations. This paper elaborates on the static structural examination concerning the heavy duty truck chassis frame to determine the response of a truck chassis under the influence of three different load considerations such as bending, torsion and combined bending and torsion load cases acting on the horizontal C-Channel. In this paper, the dimensions of a heavy vehicle chassis of a FAW dump truck vehicle is obtained from Bishoftu Automobile Industry to model and examine an heavy vehicle chassis and the conventional materials are substituted with composite materials made up of carbon-epoxy couple with E-glass epoxy with same geometry under similar pressure or load with a steel chassis. The software employed in this work is the CATIA V5 R19 to model and the ANSYS 14.5 for the finite element analysis. The result shows that composite materials mainly carbon epoxy have high load carrying capacity and higher factor of safety than to e-glass epoxy and mild steel, and the weight of the chassis is reduced by 4.8 times for carbon epoxy and 3 times for glass epoxy. Generally using composite materials for chassis frame is safe. Material substitution is the best way to reduce weight of the vehicle so as to reduce fuel consumption and atmospheric emission which is the global issue.
\end{abstract}

Keywords: Chassis, composite materials, stress, deformation

DOI: http://dx.doi.org/10.4314/ijest.v11i2.2

\section{Introduction}

Chassis as a French terminology was first used to describe the frame parts or the standard framework for vehicle. However, automotive chassis usually refers to the lower body of the vehicle, which embraces the suspension, engine, driveline, tyres, and frame. Happian (2002) identified chassis as a significant part employed in the automotive industry. Literature notes that chassis is a big structure of vehicles that dictates the shape of the vehicle. The truck used for the study is with a gross weight of $32,000 \mathrm{~kg}$. From literature information, its chassis frame comprises of $2 \mathrm{C}$-channels rails by the side and 5 cross members in the path of the 2 side rails. Other members include the gusset brackets and flat or correction plates that are positioned at the joint flanked by the side rails as well as cross members aimed to provide strength to the joints. Towards the middle is a two $\mathrm{C}$-channel cross members together forms I section to provide a better support and rigidity. The final 2 cross-members at the front and rear side are single $\mathrm{C}$ channel cross member. The present material of the truck chassis is mild steel.

The aim of this paper is to examine the performance of heavy dump truck chassis frame made up of composite material (carbon epoxy and e-glass epoxy) and mild steel of the existing material and to compare the result. The truck industrial sector is recently having elevated market demand for trucks in Ethiopia, a nation where the economic growth is extremely changing in scope periodically. A couple of industrial systems in the economy employing trucks for their businesses in the area of logistics, agriculture, even manufacturing as well as other industries. Nonetheless, the growth and creation of truck industries in Ethiopia depends extremely on imported know-how and periodically, it is difficult to respond to market forces due to costs, driving accomplishments and well as efficiency in transportation. Weight reduction is also the main issue in automotive industries. If the 
weight of the vehicle increases, the fuel consumption increases and the amount of exhaust gases emitted to the atmosphere increases which is the global issue (US Department of Energy Report, 2012).

In Ethiopia the evolutions of structural analysis in automotive industries are still far behind and research and development is not fully utilized when compared to other countries. Most of the time heavy vehicle chassis frame is manufactured with mild Steel. If steel structures are exposed to air and water, they are susceptible to corrosion. In conditions of repeated stress and more temperatures it can suffer fatigue and cracks. These are the main problems of steel and these are compensated by inducing composite materials which is discussed in this paper. In a research effort to study the chassis frame, it is important to know the following functions associated with the chassis frame. First, it offers mounting points as well as support with respect to the gearbox, steering system, engine, suspensions and the ultimate drive as well as the fuel tank together with the occupants' seating. Second, it retains the intended association that may exist between suspension as well as the steering system mounting points. Third, it offers a rigid frame work to handling in a precise manner. Fourth, it offers the occupants protection weighed against exterior impact. The needs of chassis frame are numerous, including the fact that it ought to be rigid such that it could hold shock, stresses, twist and vibrations. Second, it is supposed to be tough in a manner that resists loads due to fatigue, which are created because of the interface of the engine, road situations, driver and the power transmission. Third, it ought to absorb through the chassis on effect of depleted thresholds transition to the occupants of the vehicles as well as the environment, which reduces the opportunity of injury. The chassis frame ought to as well be light to a level to limit inertia as well as provide convincing accomplishment.

From a macroscopic combination dimension, a composite material is visualized to contain at least two components from the mechanical as well as chemical bonding view point. In composites, a "matrix phase" which could be in sheets, particles or fibres is one of the materials that the composite consists of, while the "reinforcing phase" is the other material that it comprises of (Kaw, 2006). Several composite materials provide an integration of strength as well as modulus, which may be stated to have relatively the same or preferred to the conventional metals. Since they exhibit depleted specific gravities, the ratio of strength-to-weight as well as the ratio of modulus to weight for the composites is distinctly better to the metallic counterparts. The ratios of fatigue strength weight and fatigue damage tolerances for several composite laminates are outstanding. Consequently, composites made of fiber arise to be a principal group of structural members and are contemplated for use or being thought of to replace metals for several weight-crucial parts in industries, including automotive and aerospace. The elevated damping capability of composite materials may be an advantage to several specific uses where criticality is given to hardness, noise passenger's comfort and vibration (Tapper, 2012).

As there is a sole ply or a laying such that every stratum or plies are stacked in the similar orientation, the lay-up is referred to as lamina (Figure 1). As the plies are stacked at similar angles, the word laminate describes the lay-up. It is often essential to balance the load-bearing capacity in several different orientations, for instance, the directions of $\mathrm{O}^{0}$ and $+45 \%$ as well as that of $-45^{0}$ and $90^{\circ}$ dinctions. When the same amount of plies is considered, it is referred to as being balanced, such as $0^{0}$ and $+45^{0}$ as well as $45^{\circ}$ and $90^{\circ}$ directions, referred to as quasi - isotropic laminate since it takes on the same loads in every direction of the four (Prucz et al., 2013). The composite, carbon - epoxy and e-glass epoxy employed in this work are quasi - isotropic in nature by assumption, exhibiting roughly equal property in every direction by means of $70 \%$ as well as $30 \%$ ratio for the fiber as well as epoxy, correspondingly.
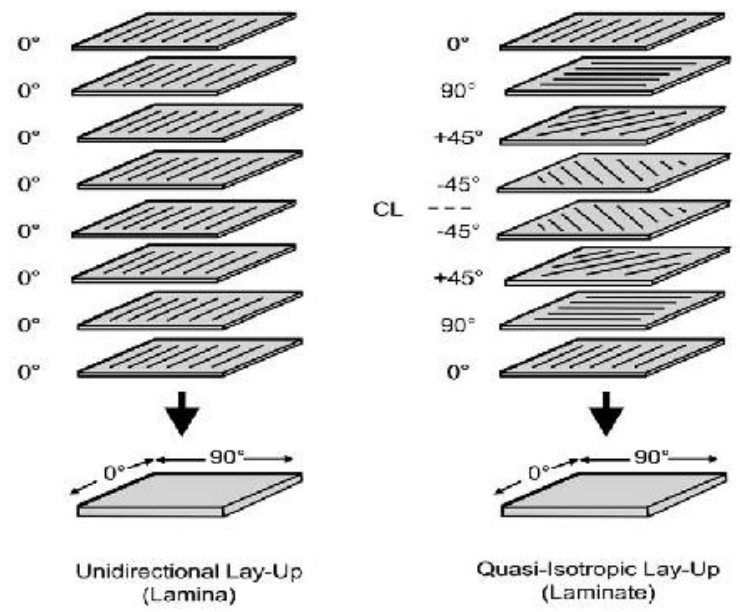

Figure 1. The difference between lamina and laminate (Prucz, et al, 2013)

\section{Methodologies and descriptions of chassis fame and materials}

The methodology intended for this thesis work is mainly modeling the frame with CATIA V5R19 and stress analysis is done with finite element analysis method commercial software called ANSYS 14.5. The specifications of the chassis frame and other data is taken from FAW dump truck assembled in Bishoftu Automotive Industry under Metal and Engineering Corporation (METEC). The general steps and methodologies of this work are described by the following flow chart (Figure 2). 


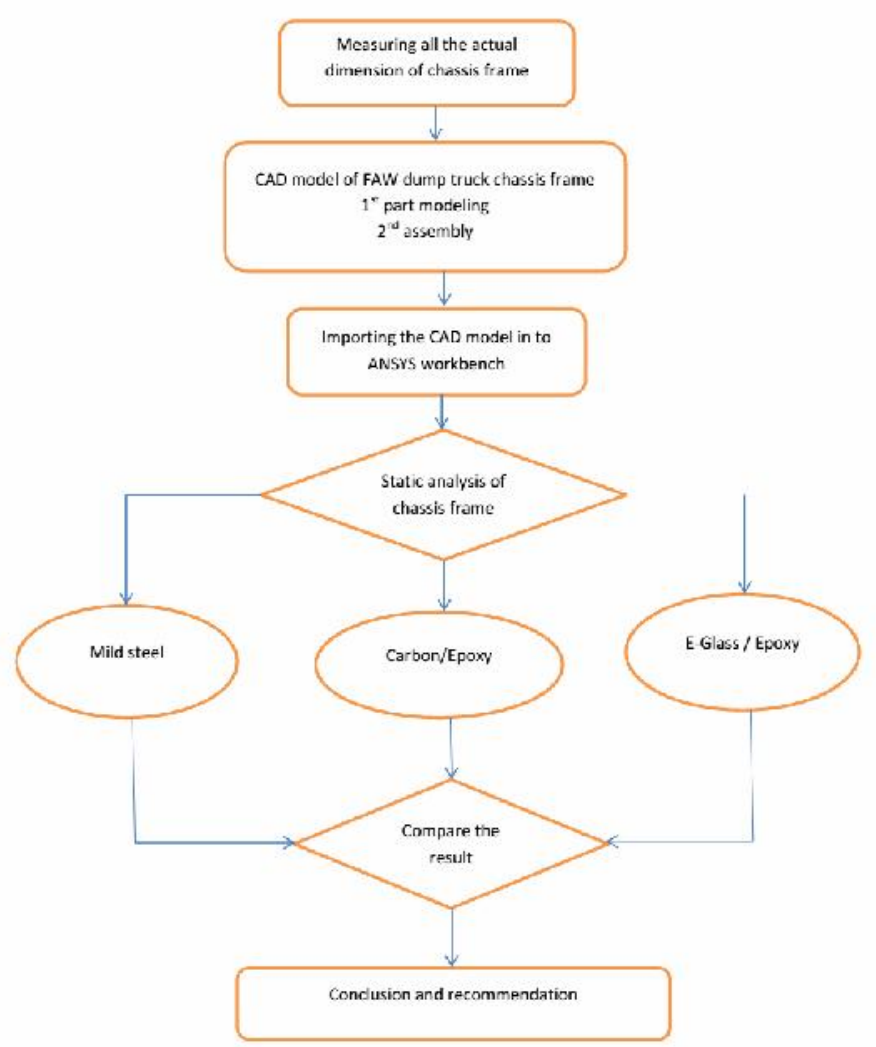

Figure 2. The chart that shows the methodology and steps of the work

\subsection{CAD model of chassis frame}

A 3D model of main frame structure is modeled using catia v5 software (Figure 3). It consists of two sides rails and five cross members. Side rails have a supporting member used as a reinforcing member of $\mathrm{C}$ channel section. Both sides of longitudinal rails at the front and rear are connected to each other similarly with a single cross member. The rest of three cross members double, two $\mathrm{C}$ channels together makes I section and connected to the side rails using connection plates. All cross members are connected to the side rails through connection plates, which are necessary to increase the load carrying capacity and use as a reinforcements.

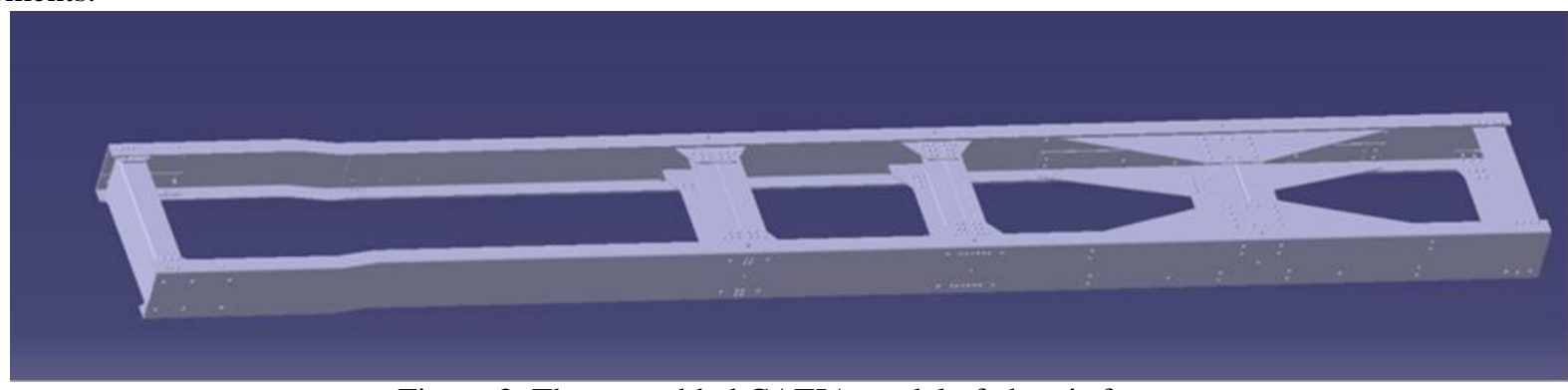

Figure 3. The assembled CATIA model of chassis frame 


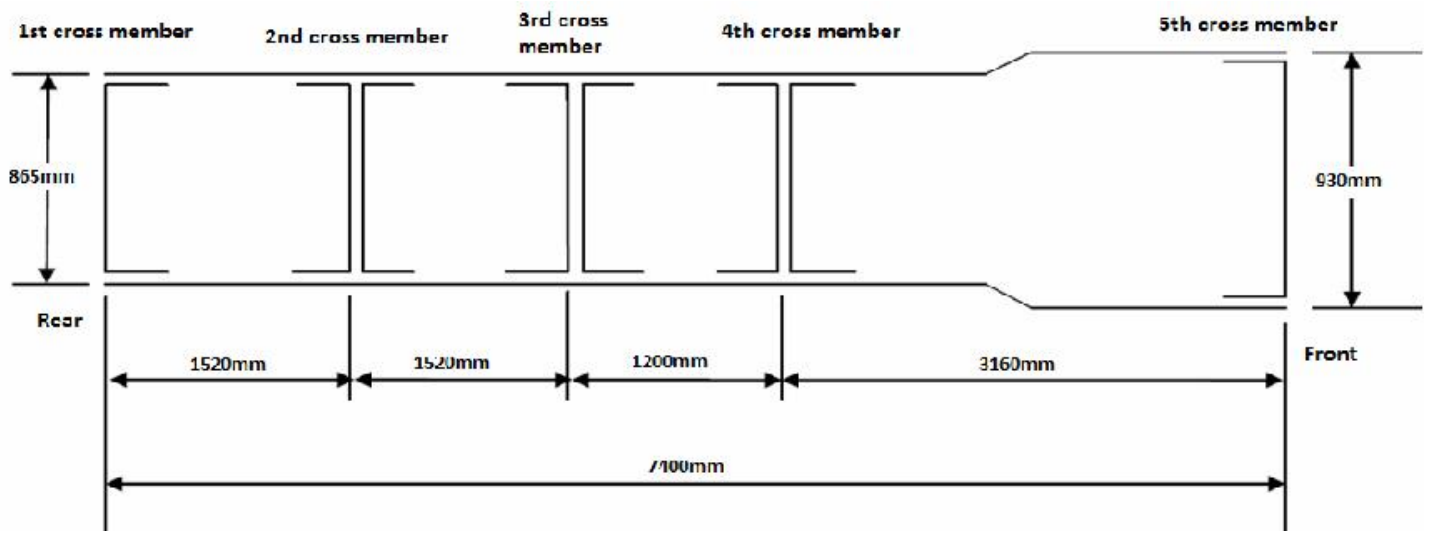

Figure 4. The dimension of FAW chassis frame from the top view

After creating the CAD model of the chassis frame (Figure 4), the next step is stress analysis by importing to the ANSYS workbench. Then static response of the chassis frame is compared between mild steel and composite materials in terms of stress and deflection as well as weight.

\subsection{Material property}

The properties of mild steel, carbon epoxy and e-glass epoxy are listed in the following table assuming quasi-isotropic which has the same property in all direction.

Table.1 Material properties of the Truck Chassis

\begin{tabular}{|l|l|l|l|}
\hline \multicolumn{5}{|c|}{ Material properties } \\
\hline Materials & Mild steel & Carbon/Epoxy & E Glass/Epoxy \\
\hline Young Modulus $\left(\mathrm{E}_{11}\right)$ & $207 \mathrm{GPa}$ & $134 \mathrm{GPa}$ & $50 \mathrm{GPa}$ \\
\hline Poisson Ratio $\left(\mathrm{v}_{11}\right)$ & 0.3 & 0.3 & 0.3 \\
\hline Density & $7800 \mathrm{~kg} / \mathrm{m}^{3}$ & $1600 \mathrm{~kg} / \mathrm{m}^{3}$ & $2600 \mathrm{~kg} / \mathrm{m}^{3}$ \\
\hline Yield stress $\left(\sigma_{11}\right)$ & $550 \mathrm{MPa}$ & $1500 \mathrm{MPa}$ & $1062 \mathrm{MPa}$ \\
\hline Ultimate stress $\left(\sigma_{11}\right)$ & $620 \mathrm{MPa}$ & $1500 \mathrm{MPa}$ & $1062 \mathrm{MPa}$ \\
\hline
\end{tabular}

\subsection{Resisting Bending Moment (RBM)}

It is defined as the Section Modulus multiplied by the yield strength and it does allow comparison of load carrying members of any shape and material. The RBM is calculated for only for one rail. Section modulus is also the combination of main side rail and supporting member (Figures 5 and 6).

$$
\begin{gathered}
\mathrm{Z}_{\mathrm{XX}}=\left(\mathrm{bh}^{3}-\mathrm{b}_{1} \mathrm{~h}^{3}\right) / 6 \mathrm{~h} \\
\mathrm{Z}_{\mathrm{XX}}=615,321.6 \mathrm{~mm} \\
\mathrm{RBM}=\mathrm{Z}_{\mathrm{XX}} \times \sigma_{\mathrm{y}}
\end{gathered}
$$

For mild steel

$\mathrm{RBM}=\mathrm{Z}_{\mathrm{XX}} \times \sigma_{\mathrm{y}}$

$\mathrm{RBM}=615,321.6 \mathrm{~mm}^{3} \times 550 \mathrm{~N} / \mathrm{mm}^{2}=338,426,880 \mathrm{Nmm}=338.426 \mathrm{kNm}$

For carbon epoxy

$\mathrm{RBM}=\mathrm{Z}_{\mathrm{XX}} \times \sigma_{\mathrm{y}}$

$R B M=615,321.6 \mathrm{~mm}^{3} \times 1500 \mathrm{~N} / \mathrm{mm}^{2}=922982400 \mathrm{Nmm}=992.98 \mathrm{kNm}$

For e glass epoxy

$\mathrm{RBM}=\mathrm{Z}_{\mathrm{XX}} \times \sigma_{\mathrm{y}}$

$R B M=615,321.6 \mathrm{~mm}^{3} \times 1062 \mathrm{~N} / \mathrm{mm}^{3}=653,471,539.2 \mathrm{Nmm}=635.47 \mathrm{kNm}$ 


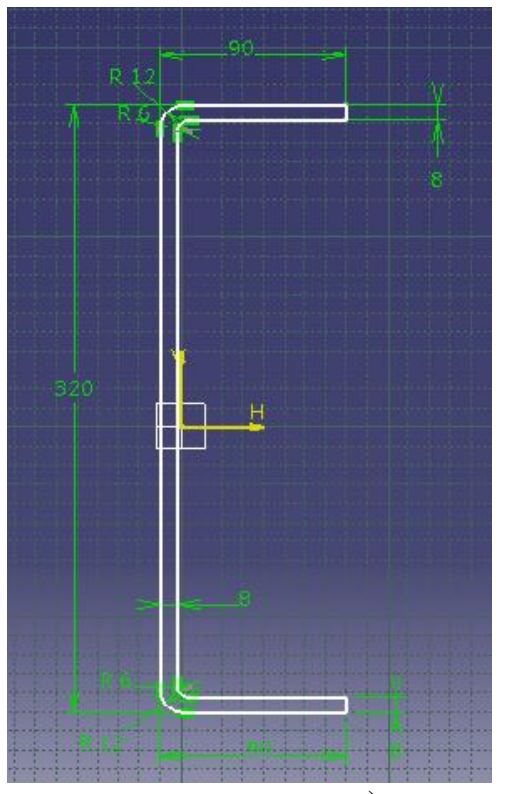

a)

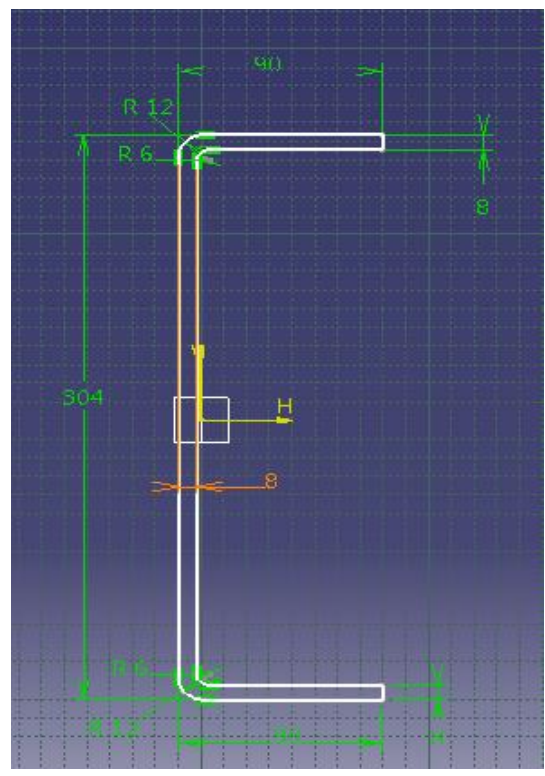

b)

Figure 5. The specification of C-channel a) main side rail b) supporting member

\section{Resistance bending moment (kNm)}

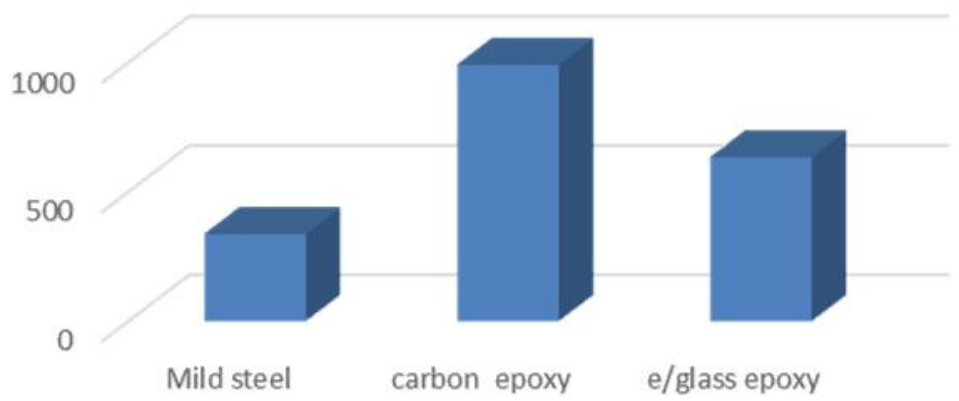

Figure 6. Resistant bending moment for steel, carbon epoxy and e-glass epoxy

From the above results, composite materials have higher resisting bending moment than mild steel. That means composite material especially carbon epoxy chassis frame have a greater load carrying capacity as compared to other materials.

\subsection{Weight comparison}

Reductions in vehicle weight can be achieved by three methods such as material substitution, vehicle redesign, and vehicle downsizing. In this work material substitution used which involves replacing heavier iron and steel used in vehicles with weightsaving materials like aluminum, magnesium, and plastics and polymer composites (Prucz, et al, 2013). When heavy weight materials are replaced by lightweight materials it is possible to reduce the weight of vehicles. Here using carbon epoxy and e glass epoxy it is saved $913.23 \mathrm{~kg}$ and $765.94 \mathrm{~kg}$ respectively. The total volume of frame is $0.14729 \mathrm{~m}^{3}$, when this volume is multiplied by the density of the respective material we can get the mass of the frame for each materials (Figure 7).

Mass $=$ Volume $\times$ Density

$$
\mathrm{m}=\mathrm{v} \times \rho
$$

Table 3. Weight comparison of steel and composite materials

\begin{tabular}{|l|l|l|l|}
\hline Materials & Weight $(\mathrm{kg})$ & Saved weight $(\mathrm{kg})$ & Weight reduction in percent $(\%)$ \\
\hline Mild steel & 1148.9 & - & - \\
\hline Carbon epoxy & 235.67 & 913.23 & 79.48 \\
\hline E glass epoxy & 382.96 & 766.24 & 66.67 \\
\hline
\end{tabular}




\section{Mass of frame}

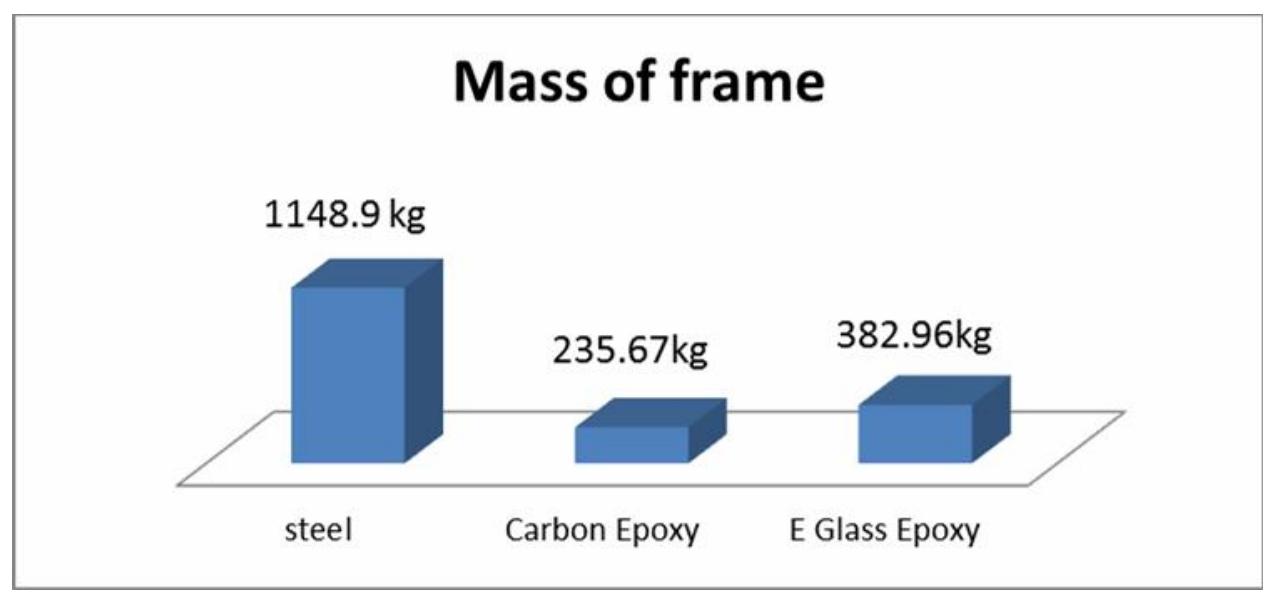

Figure 7. The mass of frame for each material

\section{Analysis, result and discussion}

This simulation is based on the condition of the truck being stationary. The stress distribution on the chassis for bending, torsion and combined bending and torsion load have been determined. According to the equation of equilibrium condition, the vertical tire reaction forces act upward direction and body weight with payload act on downward direction (Asker, et al., 2012; Zaman, 2005). The most important load cases are those of bending, torsion and combined bending and torsion are paramount in determining a satisfactory structure (Pawlowski, 1964). These listed load cases are simulated with FEM commercial software of ANSYS workbench 14.5 to know the response of the chassis frame in terms of stress and deformation. The basic equation governing static equilibrium condition of the system is given in equation below (Madenci and Guven, 2007).

$[\mathrm{K}]\{\mathrm{q}\}=\{\mathrm{F}\}$

Where, $[\mathrm{K}]$ is global stiffness matrix

$\{\mathrm{q}\}$ is nodal displacement vector

$\{\mathrm{F}\}$ is the load vector

The global stiffness matrix is taken as the summation of element matrices, i.e.

$[\mathrm{K}]=\sum_{1}^{n} K e$

In this static analysis for all load cases there are various steps that are to be followed. They are mesh generation, fixed supports, application of loads and evaluating result. The element type used for this analysis is ten node tetrahedral elements as follows (Figure 8).

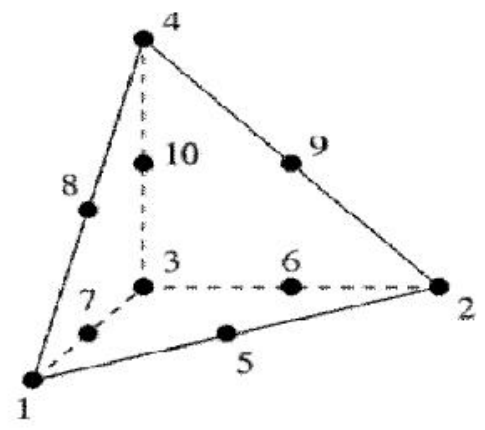

Figure 8. Ten node tetrahedral element (Madenci and Guven, 2007)

\subsection{Bending load case}

The ladder frame chassis conceived as a merely supported beam while the load was the effect of the weight of the components that was applied to the beam. The spring hangers ended the distribution of the support load from the axles (Abd-Rahman et al., 2008). The reaction of the axle load was achieved through the resolution of the forces together with taking moments from the weights as well as the components position. In real life computation, it was given that the load that falls or the chassis frame such as the weight of itself, has concentration on a little amount of points. The equivalence of these point leads in the particular spreading of the load carried through the vehicle (Rajappan et al, 2013). The meshing is done on the model with 203,977 numbers of nodes and 93,699 numbers of ten node tetrahedral elements (Figure 9). When meshing the sizing of mesh is done with fine relevance center and higher smoothing. 


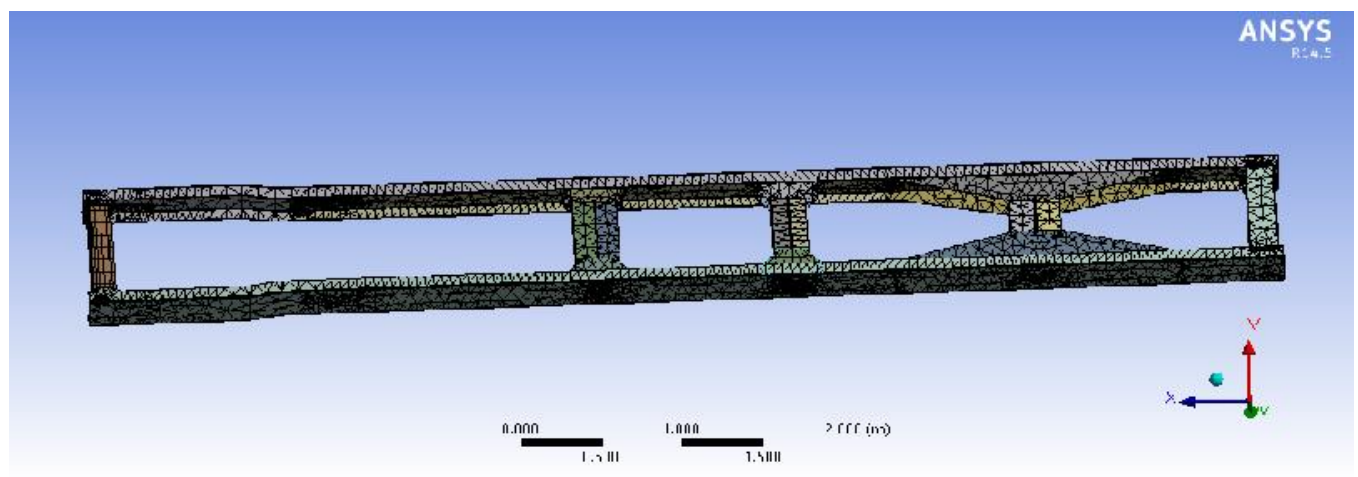

Figure 9. Meshing of the model

\section{A. Boundary condition and application of the load (Figure 10)}

The load is applied on the upper flange of side rails where the pay load has contact with the frame (Rajappan et al, 2013).

Total gross vehicle mass $(\mathrm{GVM})=32000 \mathrm{~kg}$

Total weight $=\mathrm{GVM} \times$ gravity

$$
\begin{aligned}
& \mathrm{W}=\mathrm{m} \times \mathrm{g} \\
& =32000 * 9.81=313,920 \mathrm{~N}=313.92 \mathrm{KN}
\end{aligned}
$$

As the frame supports the body by its two side frames the load on each side members

$$
=313,920 \mathrm{~N} / 2=156,960 \mathrm{~N}=156.96 \mathrm{KN}
$$

Taking the load as a uniformly distributed load (UDL),

The total area on which the UDL is placed $=$ the length of side beam * width of side beam

$$
\begin{aligned}
\mathrm{A} & =\mathrm{L} \times \mathrm{b} \\
& =7400 \mathrm{~mm} * 90 \mathrm{~mm}=666,000 \mathrm{~mm}^{2} \\
\mathrm{P} & =\mathrm{W} / \mathrm{A}
\end{aligned}
$$

The total pressure applied $=$ total load $/$ total area $=156,960 \mathrm{~N} / 666,000 \mathrm{~mm}^{2}=0.2356 \mathrm{~N} / \mathrm{mm}^{2}$

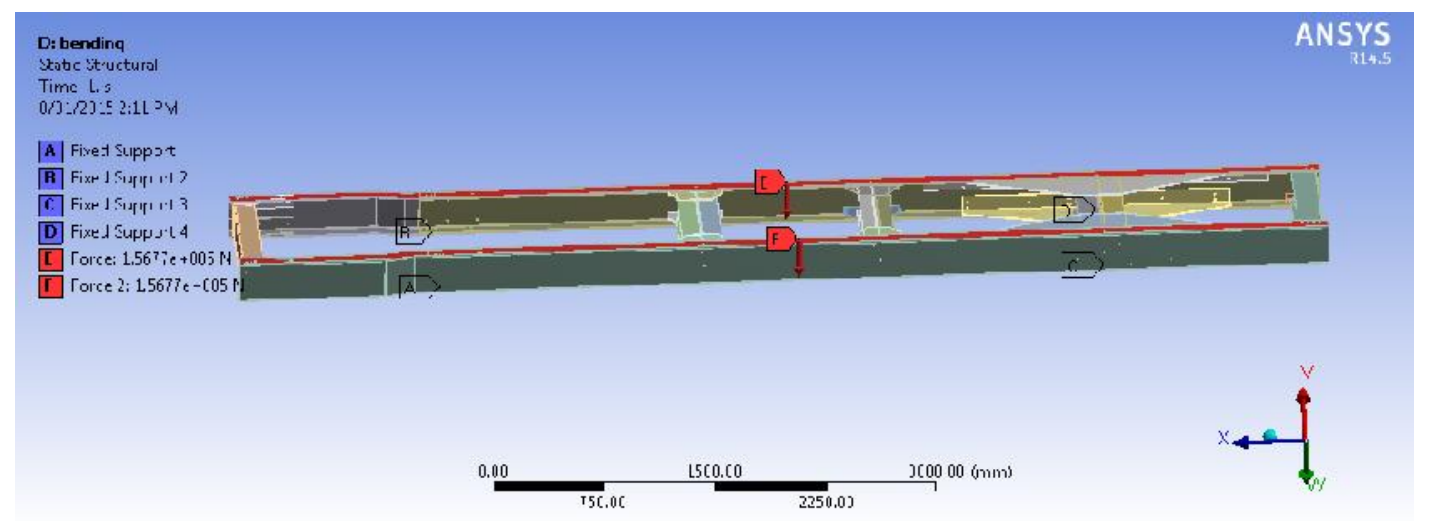

Figure 10. Boundary condition and application of bending load

\section{B. The stress distribution and deformation of mild steel}

There are many types of stresses developed in a component. The frame is analyzed by considering Equivalent (vonmises) stress. According to the maximum distortion energy theory, failure or yielding occurs when the Von Mises stress reaches the yield strength (Muhammad, et al, 2012). So vonmises stress is the best predictor of yielding. According to the maximum distortion energy theory, failure or yielding occurs when the Von Mises stress reaches the yield strength. So vonmises stress is the best predictor of yielding. Factor of safety is the ratio yield strength of the material property to vonmises stress developed due to the applied bending load. The maximum deformation $1.7046 \mathrm{~mm}$ and minimum deformation $0 \mathrm{~mm}$ is obtained at the middle of the frame and front fixed support respectively. The factor of safety of mild steel chassis frame due to bending load case is 1.48 ; hence the equivalent stress is less than the yield stress (Figure 11). 


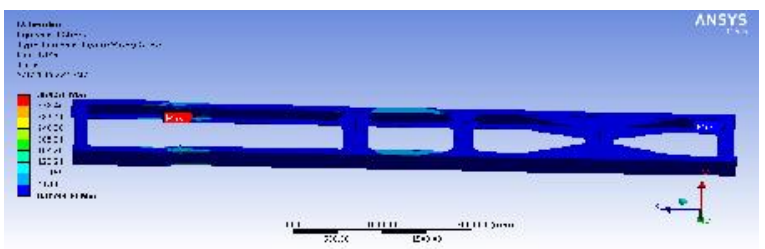

Figure 11. a) Equivalent stress of mild steel

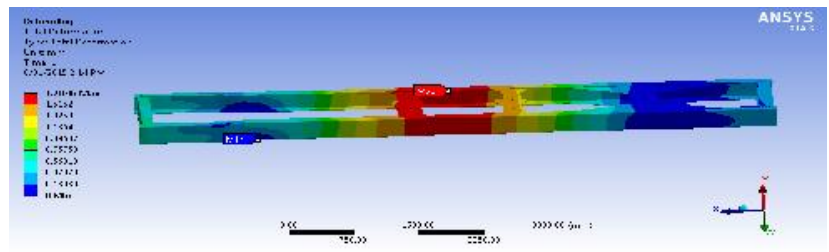

b) Deformation on mild steel frame

\section{Stresses distribution and deformation of carbon epoxy (Figure 12)}

The maximum deformation of carbon epoxy frame is $2.6364 \mathrm{~mm}$ at the middle of the frame and the factor of safety of carbon epoxy frame due to bending load case is 4.057 means the ultimate strength of carbon epoxy is $1500 \mathrm{MPa}$ which is four times greater than the equivalent stress developed on the frame, so that the design is safe.

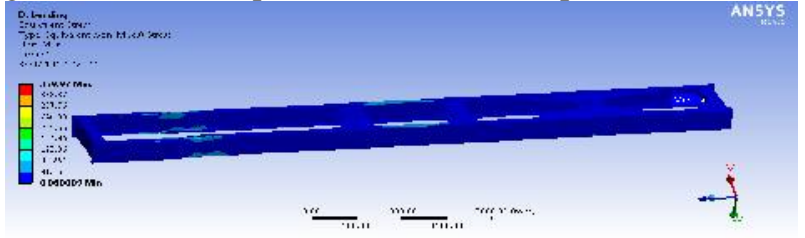

Figure 12. a) Stress distribution on carbon epoxy

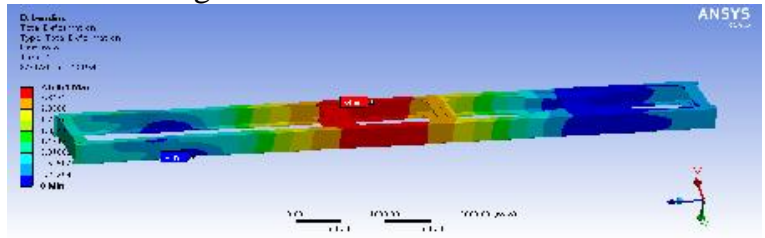

b) Deformation on carbon epoxy

D. Stresses distribution and deformation of e glass epoxy (Figure 13)

The maximum deformation of e glass epoxy frame is $7.0656 \mathrm{~mm}$ which is obtained at the middle and minimum at the front fixed support. and the factor of safety of e glass epoxy chassis frame due to bending load case is 2.87 . The

ultimate strength of e glass epoxy is $1062 \mathrm{MPa}$ which is three times greater than the stress developed in the frame.

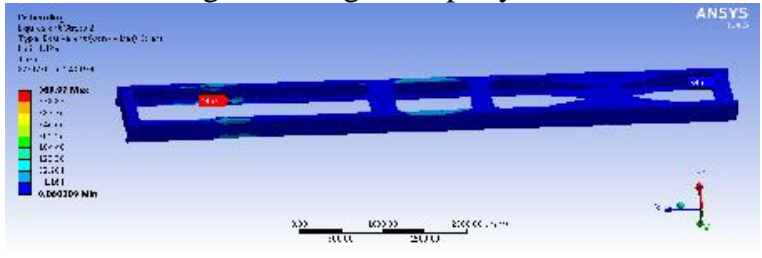

Figure13. Stress distribution on e-glass epoxy frame

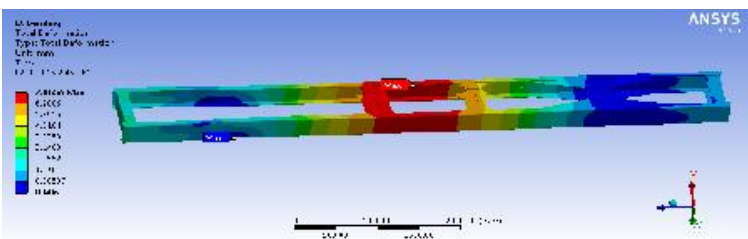

b) deformation on e-glass epoxy frame

Table 4. Comparative Analysis of steel chassis and polymeric composite chassis for bending load cases.

\begin{tabular}{|l|l|l|l|l|}
\hline No. & Parameters & steel & Carbon epoxy & E glass epoxy \\
\hline 1 & Factor of safety & 1.48 & 4.057 & 2.87 \\
\hline 2 & Deformation & $1.7046 \mathrm{~mm}$ & $2.6364 \mathrm{~mm}$ & 7.656 \\
\hline
\end{tabular}

The result shows that carbon epoxy material has superior performance of load carrying capacity with higher factor of safety than mild steel followed by e-glass epoxy.

\subsection{Torsion load case (Figure 14)}

This simulation was carried out on the assumption that a truck's front wheel is positioned to rest on a lump. The result of this is that torsion develops on chassis. The absolute torsion load situation may not happen in practice. However, it is necessary since it creates extremely different internal load in structure (Happian-Smith, 2002)

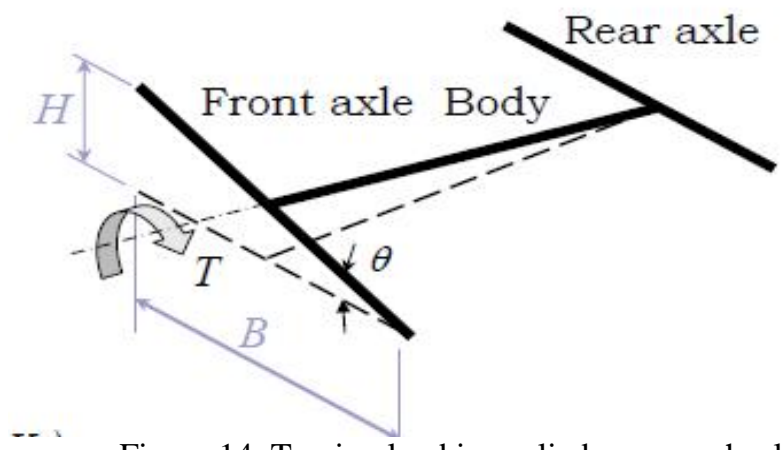

Figure 14. Torsion load is applied on one wheel 
Torque $T$ will reach a limit when right wheel lifts off, i.e., when $P_{R}=0$.The front axle is the lightest load axle, from the manual the front axle weight is $6500 \mathrm{~kg}$, then

$\mathrm{P}_{\mathrm{L}}=\mathrm{P}_{\mathrm{axle}}=6500 \times 9.81=63765 \mathrm{~N}$

\section{A. Boundary condition and application of the load (Figure 15)}

As it is shown from the figure below A, B and C are fixed supports at the wheel found at level ground. Torsion load is applied on the front axle left wheel $63,765 \mathrm{~N}$ at $\mathrm{D}$ where the wheel gets a hump.

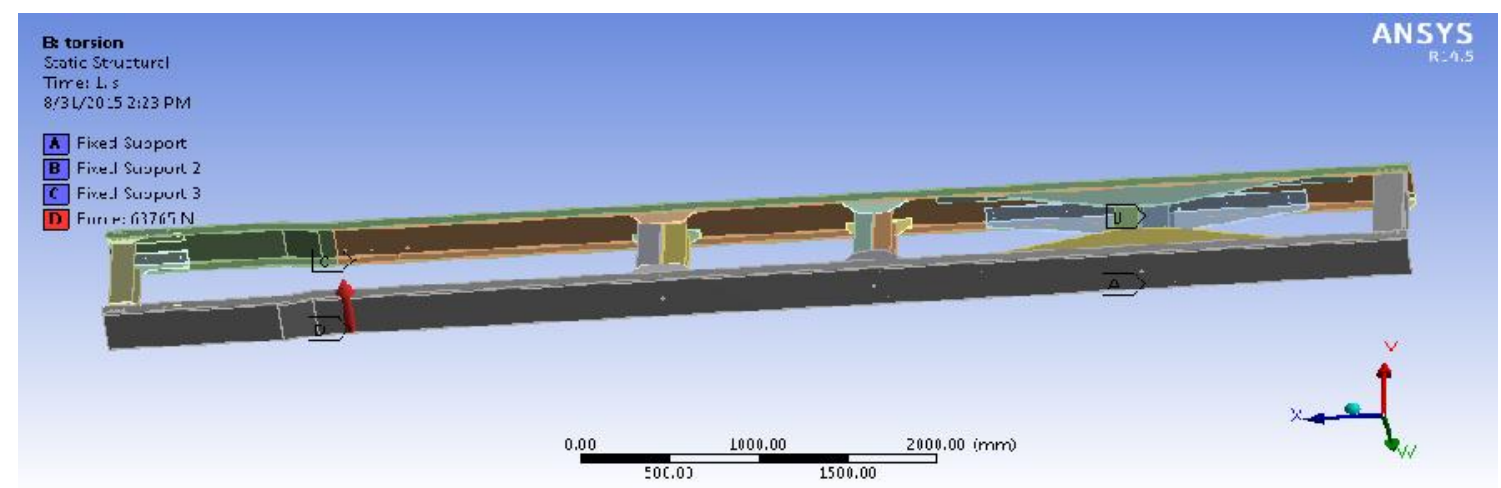

Figure 15. Boundary condition and application of torsion load

A. Stress distribution and deformation of mild steel (Figure 16)

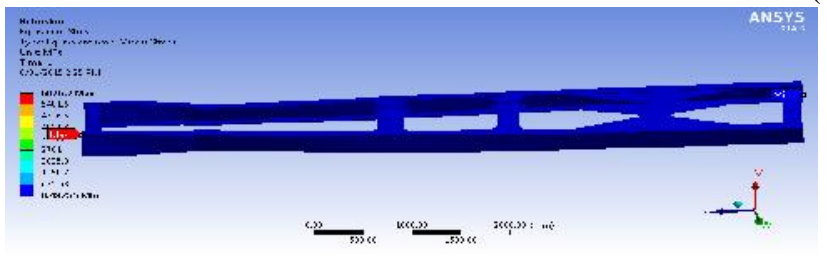

Figure 16. a) Stress distribution on mild steel frame

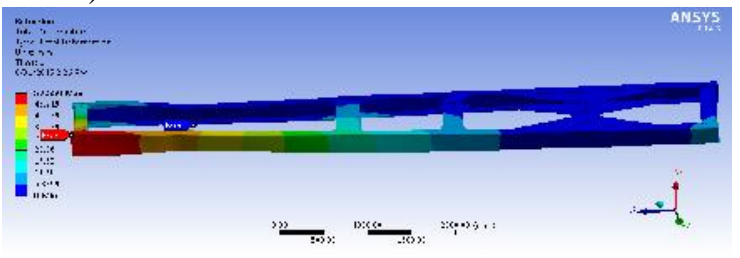

b) Deformation on mild steel frame

B. Stress distribution and deformation of carbon epoxy (Figure 17)

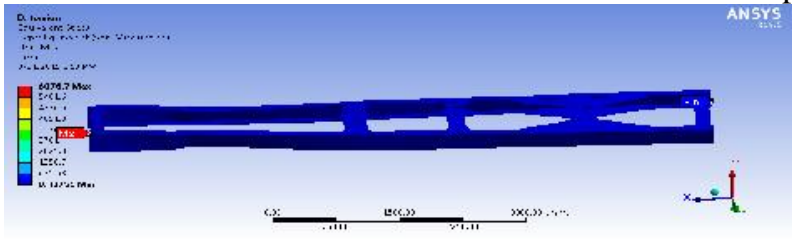

Figure 17 a) Stress distribution on carbon epoxy frame

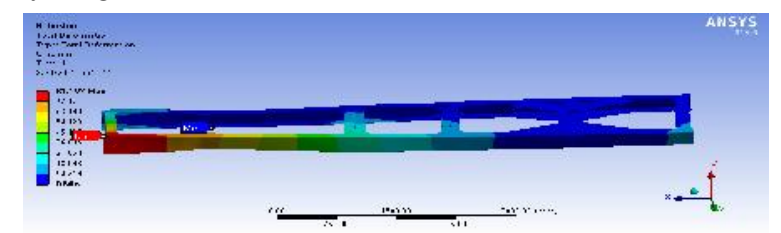

b) Deformation on carbon epoxy frame

C. Stress distribution and deformation of e glass epoxy (Figure 18)

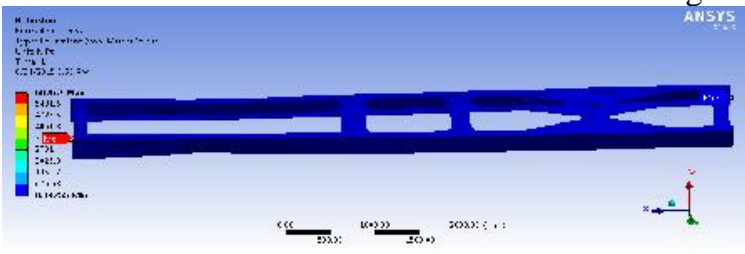

Figure 18 stress distribution on e-glass epoxy frame

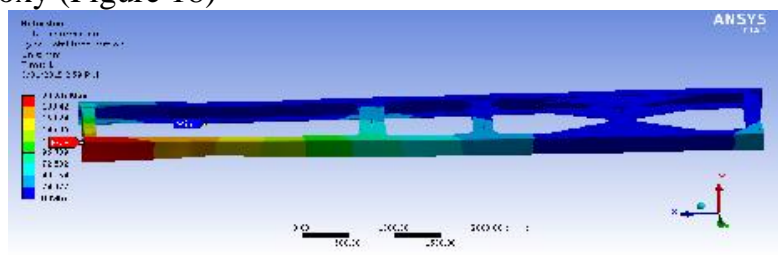

b) deformation on e-glass epoxy frame

Table 5. Comparative Analysis of steel heavy vehicle chassis and polymeric composite heavy vehicle chassis for torsion case

\begin{tabular}{|l|l|l|l|l|}
\hline S.No. & Parameters & Steel & Carbon epoxy & E glass epoxy \\
\hline 1 & Equivalent stress & $6076.7 \mathrm{MPa}$ & $6076.7 \mathrm{MPa}$ & $6076.7 \mathrm{MPa}$ \\
\hline 2 & Deformation & $52.559 \mathrm{~mm}$ & $81.129 \mathrm{~mm}$ & $217.6 \mathrm{~mm}$ \\
\hline
\end{tabular}

The maximum equivalent stress (vonmisses stress) is developed at the front end of the frame rail imposed by the torsion load and the stress is minimum at the opposite rear end of the frame rail. This stress value is greater than the yield stress and ultimate 
strength of all three proposed materials. if the frame is subjected to this much amount of torsional load, even if it could not occur in practice, the frame will fail automatically.

The maximum deformation of mild steel, carbon epoxy and e-glass epoxy is $52.559 \mathrm{~mm}, 81.192 \mathrm{~mm}$ and $217.6 \mathrm{~mm}$ obtained at the front end where the torsional equivalent stress is maximum respectively.

\subsection{Combined bending and torsion load case}

A. Boundary condition and application of the load (Figure 19)

As it is shown from the figure below A, B and C are fixed supports at the wheel found at level ground. Torsion load is applied on the front axle left wheel $63,765 \mathrm{~N}$ at D where the wheel gets a hump. Bending load due to the weight of the components and payload is also applied (Fui et al., 2007,) at each side rails 156,960 N at E and F.

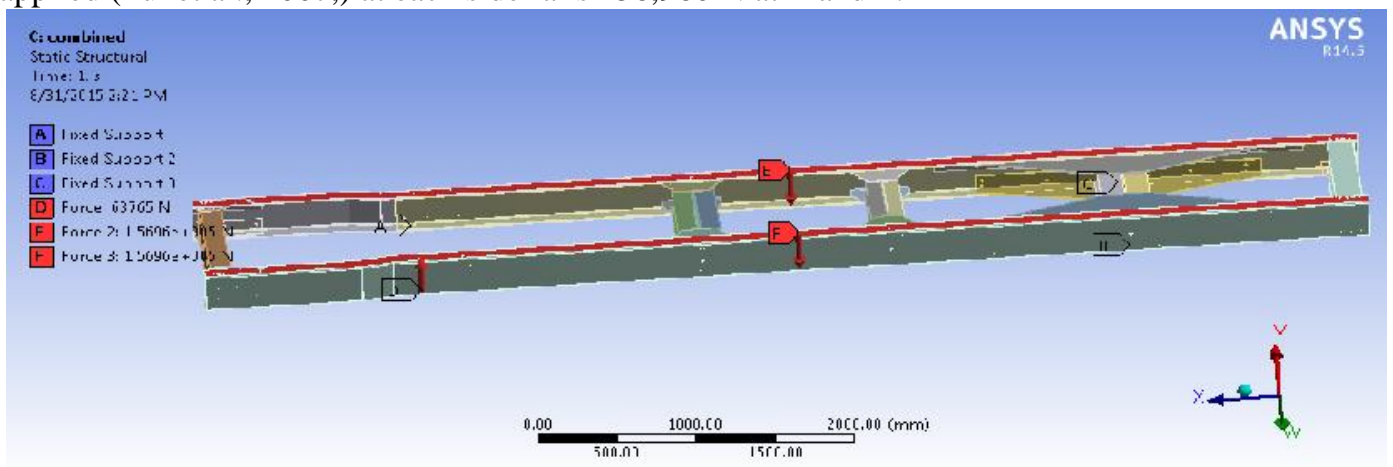

Figure 19. Boundary condition and application of combined bending and torsion load case

\section{B. Stress distribution and deformation of mild steel (Figure 20)}

The maximum equivalent stress developed in the frame of mild steel is obtained at the front end of the frame rail at the side torsion load is subjected. This magnitude of stress is greater than or beyond the yield strength and ultimate strength of the steel of $550 \mathrm{MPa}$ and $620 \mathrm{MPa}$ respectively. So the frame will fail if it is subjected to this magnitude of torsion load, the design is no safe. For the design to be safe the tress developed on the frame has to be less than the yield strength of the material.

The factor of safety of mild steel due to combined and bending torsion load is 0.43 and the maximum deformation is $12.221 \mathrm{~mm}$ at the front end of the frame where the stress is maximum at the front end.

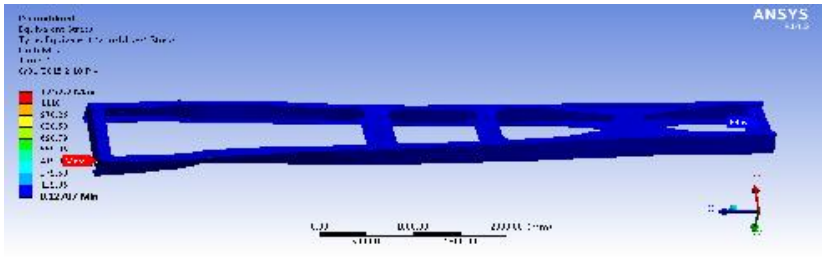

Figure 20. a) Stress distribution on mild steel frame

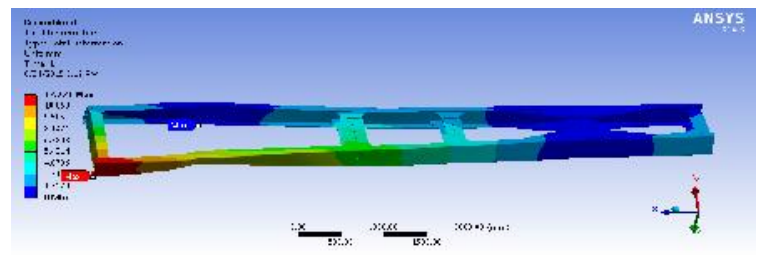

b) deformation on mild steel frame

\section{Stress distribution of carbon epoxy (Figure 21)}

The factor of safety (FOS) of carbon epoxy frame due to combined bending and torsion load case is 1.19 and the maximum deformation of carbon epoxy frame is $18.878 \mathrm{~mm}$ at the front end.

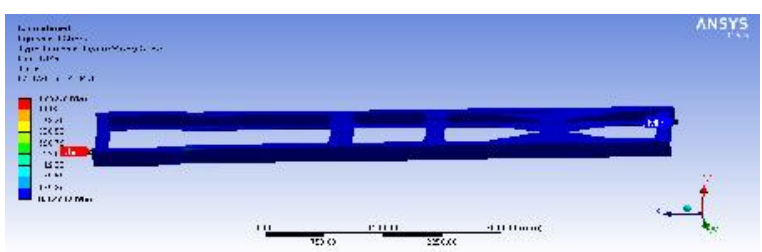

Figure 21 a) stress distribution on carbon epoxy frame

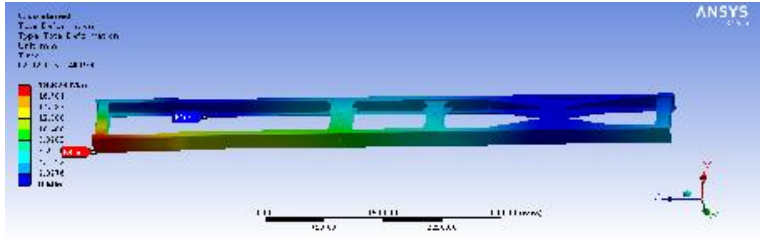

b) deformation on carbon epoxy frame

\section{Stress distribution and deformation of e glass epoxy (Figure 22)}

The factor of safety (FOS) of e-glass epoxy frame due to combined bending and torsion load case is 0.85 and the maximum deformation of carbon epoxy frame is $50.594 \mathrm{~mm}$ at the front end. 


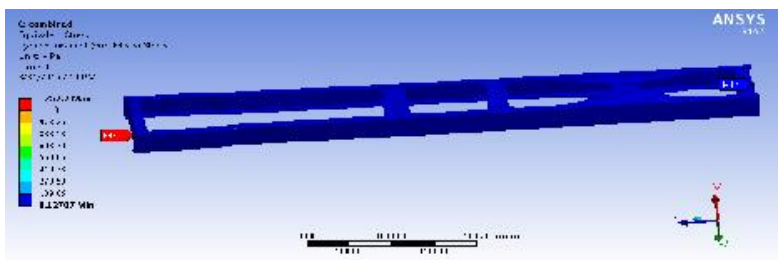

Figure 22a) stress distribution on e-glass epoxy frame

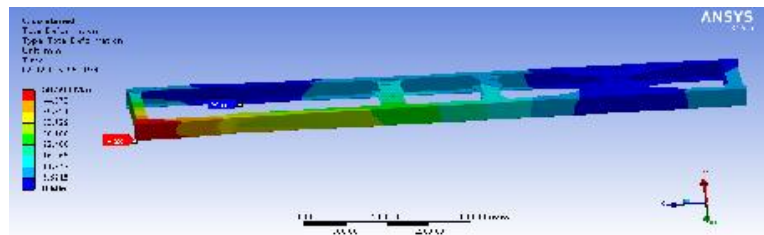

b) deformation on e-glass epoxy frame

Table 7. Comparative Analysis of steel heavy vehicle chassis and polymeric composite heavy vehicle chassis for combined bending and torsion case

\begin{tabular}{|c|c|c|c|c|}
\hline S.No. & Parameters & Steel & Carbon epoxy & E glass epoxy \\
\hline 1 & Factor of safety & 0.43 & 1.19 & 0.85 \\
\hline 2 & Deformation & $12.221 \mathrm{~mm}$ & $18.878 \mathrm{~mm}$ & $50.594 \mathrm{~mm}$ \\
\hline
\end{tabular}

From the linear static analysis of FAW truck chassis frame, for all load cases it is obtained that the maximum stress area is around the front end, because the distance between the front two cross members (i.e. fifth and fourth cross members) is relatively high. There should be other cross member in between these two cross members to minimize the stress.

\section{Conclusions}

This paper considered composites of the carbon epoxy and the E-glass epoxy types as chassis materials for free load cases as pure bending load, pure torsion heed and the combination of bending and torsion load case. Through the observation of the outcome of structural analysis, the stress value obtain was not up to their corresponding permissible stress values or ultimate strength hence their factors of safety are greater than mild steel. Thus, employing composites for chassis appears safe by the calculations. Through the replacement of steel with composites, there is a reduction in the weight of the chassis by 4.8 multiples for carbon epoxy and 3 times for glass epoxy since the density of steel appears greater than that of the composite. Through the use of a polymeric composite, heavy vehicle chassis for similar load carrying capability, there exists a 79-48\% weight reduction for carbon epoxy and $66.67 \%$ for E-glass epoxy. Examining the outcome, it is noted that the composite (polymeric) heavy vehicle chassis is not as heavy as the traditional steel and even stronger than it when the chassis is made of the materials. However, the same design specifications were used. Material substitution is the best way to reduce weight of the vehicle so as to reduce fuel consumption and emission which is the global issue.

$\begin{array}{cl}\text { Nomenclature } & \\ \mathrm{F} & \text { Force matrix } \\ \mathrm{K} & \text { Stiffness matrix } \\ \mathrm{U} & \text { Displacement matrix } \\ \mathrm{I}_{\mathrm{XX}} & \text { Moment of inertia about } \mathrm{X} \text { axis } \\ \mathrm{b} & \text { Base of the section } \\ \mathrm{h} & \text { Height of the section } \\ \mathrm{Z}_{\mathrm{XX}} & \text { section modulus } \\ \sigma_{\mathrm{y}} & \text { yield strength } \\ \mathrm{RBM} & \text { resisting bending moment } \\ \sigma_{\mathrm{ult}} & \text { Ultimate strength } \\ \mathrm{E} & \text { Young's modulus }\end{array}$

$\begin{array}{ll}\mathrm{P} & \text { Density } \\ \mathrm{T} & \text { Torsion } \\ \mathrm{P}_{\mathrm{L}} & \text { Left wheel loads } \\ \mathrm{P}_{\mathrm{R}} & \text { right wheel loads } \\ \mathrm{B} & \text { Track length } \\ \mathrm{H} & \text { Bump height } \\ \mathrm{P}_{\text {axle }} & \text { axle loads } \\ \mathrm{Ke} & \text { element stiffness matrix } \\ \mathrm{K} & \text { global stiffness matrix } \\ \mathrm{Me} & \text { element mass matrix } \\ \mathrm{M} & \text { global mass matrix }\end{array}$

\section{Acknowledgment}

Authors are thankful to Bishoftu Automotive Industry and Ethiopian Plastic Industry for allowing us to do this work in their industry.

\section{References}

Asker H.K., Dawood T.S. and Said A.F., 2012, Stress analysis of standard truck chassis during ramping on block using finite element method, ARPN Journal of Engineering and Applied Sciences, Vol.. 7, No. 6, pp. 641-648

Chinnaraj K., Prasad M.S., Rao C.L., 2008, Experimental analysis and quasi static numerical idealization of dynamic stresses on a heavy vehicle chassis frame assay, Journal of Applied Mechanics of Materials, Vols. 13-14, pp. 271-280.

Chinnaraj K., Prasad M.S. and Rao C L., 2008 "Experimental analysis and quasi-static numerical idealization of dynamic stresses on a heavy truck chassis frame assembly, Applied Mechanics and Materials, Vols. 13, pp. 271-280,. 
Design MV, 2002, An Introduction to Modern Vehicle Design, in Happian-Smith J, Reed Educational and Professional Publishing Ltd., Oxford, UK

Fui T.H., Rahman R.A., 2007, Statics and dynamics structural analysis of a 4.5 ton truck chassis, Journal Mekanikal, No. 24, p. 5667

Ingole N. K. and Bhope D.V., 2011, Stress analysis of tractor trailer chassis for self-weight reduction, International Journal of Engineering Science and Technology, Vol. 3 No. 9, pp. 7218-7225

Karao lu C, Kuralay N, 2002, Stress analysis of a truck chassis with riveted joints, Finite Elements in Analysis and Design, Vol. 38 , No. 12, pp. 1115-1130

Kaw, A.K., 2006, Mechanics of Composite Materials-Second Edition." CRC Press, Taylor and Francis Group, Boca Raton, Florida, USA,

Madenci E. and Guven I., 2007, The finite element method and applications in engineering using ANSYS, Springer Publisher

Nor MAM, Rashid H, Faizul WM, Mahyuddin W, Azlan MAM, Mahmud J., 2012, Stress analysis of a low loader chassis, Procedia Engineering, Vol. 41, pp. 995 - 1001

Prucz JC, Shoukry SN, William GW, Shoukry MS, 2013, Lightweight composite materials for heavy duty vehicles, US Department of Energy, Office of Energy Efficiency and Renewable Energy, National Energy Technology Laboratory final report, Morgantown, West Virginia, USA.

Rajappan R. and Vivekanandhan M. 2013, Static and modal analysis of chassis by using FEA, International Journal of Engineering and Science, Vol. 2, No. 2, pp. 63-73

Rahman RA, Tamin MN, Kurdi O., 2008, Stress analysis of heavy duty truck chassis as a preliminary data for its fatigue life prediction using FEM, Jornal Mekanikal, No. 26, 76-85.

Tapper R., 2012, Composite developments for light weighting heavy duty vehicles, University of Bristol,

Workshop Report: 2013, Trucks and heavy-duty vehicles technical requirements and gaps for lightweight and propulsion materials, US Department of Energy, Energy Efficiency and Renewable Energy and Vehicle Technologies Office Final report.

Zaman IB, 2005, Study of dynamic behaviour of truck chassis, M.Sc. Thesis, Faculty of Mechanical Engineering, Universiti Teknologi Malaysia, Malaysia.

Received July 2018

Accepted January 2019

Final acceptance in revised form February 2019 